\title{
Defect Diffusion during Annealing of Low-Energy Ion-Implanted Silicon
}

\author{
P.J. Bedrossian, M.-J. Caturla, T. Diaz de la Rubia
}

This article was submitted to Materials Research Society Conference "Microstructure Evolution during Irradiation, Boston, MA, December 2-5, 1996

\section{March 8, 2001}

U.S. Department of Energy

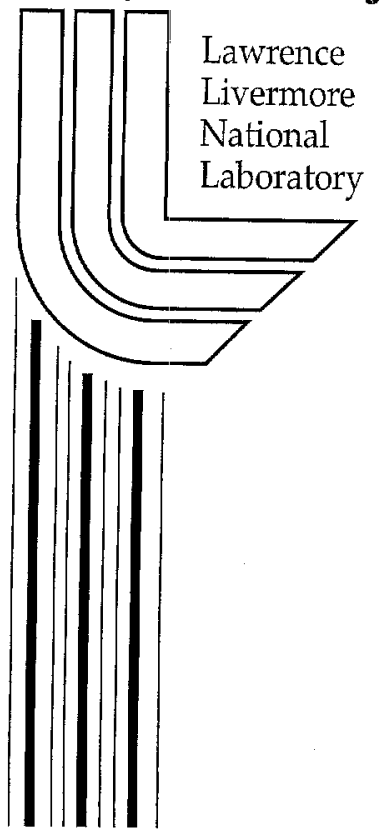




\section{DISCLAIMER}

This document was prepared as an account of work sponsored by an agency of the United States Government. Neither the United States Government nor the University of California nor any of their employees, makes any warranty, express or implied, or assumes any legal liability or responsibility for the accuracy, completeness, or usefulness of any information, apparatus, product, or process disclosed, or represents that its use would not infringe privately owned rights. Reference herein to any specific commercial product, process, or service by trade name, trademark, manufacturer, or otherwise, does not necessarily constitute or imply its endorsement, recommendation, or favoring by the United States Government or the University of California. The views and opinions of authors expressed herein do not necessarily state or reflect those of the United States Government or the University of California, and shall not be used for advertising or product endorsement purposes.

This is a preprint of a paper intended for publication in a journal or proceedings. Since changes may be made before publication, this preprint is made available with the understanding that it will not be cited or reproduced without the permission of the author.

This report has been reproduced directly from the best available copy.

Available electronically at http://www.doe.gov/bridge

Available for a processing fee to U.S. Department of Energy and its contractors in paper from

U.S. Department of Energy

Office of Scientific and Technical Information

P.O. Box 62

Oak Ridge, TN 37831-0062

Telephone: (865) 576-8401

Facsimile: (865) 576-5728

E-mail: reports@adonis.osti.gov

Available for the sale to the public from

U.S. Department of Commerce

National Technical Information Service

5285 Port Royal Road

Springfield, VA 22161

Telephone: (800) 553-6847

Facsimile: (703) 605-6900

E-mail: orders@ntis.fedworld.gov

Online ordering: http://www.ntis.gov/ordering.htm

OR

Lawrence Livermore National Laboratory

Technical Information Department's Digital Library

http://www.llnl.gov/tid/Library.html 


\title{
DEFECT DIFFUSION DURING ANNEALING OF LOW-ENERGY ION-IMPLANTED SILICON
}

\author{
P. J. BEDROSSIAN *, M.-J. CATURLA, AND T. DIAZ DE LA RUBIA \\ Lawrence Livermore National Laboratory, Livermore CA 94551 \\ *bedrossian1@LLNL.gov
}

\begin{abstract}
We present a new approach for investigating the kinetics of defect migration during annealing of low-energy, ion-implanted silicon, employing a combination of computer simulations and atomic-resolution tunneling microscopy. Using atomically-clean Si(111)-7x 7 as a sink for bulk point defects created by $5 \mathrm{keV} \mathrm{Xe}$ and Ar irradiation, we observe distinct, temperature-dependent surface arrival rates for vacancies and interstitials. A combination of simulation tools provides a detailed description of the processes that underly the observed temperature-dependence of defect segregation, and the predictions of the simulations agree closely with the experimental observations.
\end{abstract}

\section{INTRODUCTION}

The kinetics of point defects in silicon have generated controversy for many years $[1,2,3,4]$. In particular, while recent Molecular Dynamics (MD) simulations indicate lower binding energies for vacancy clusters than for interstitials [5], supporting experimental data are scarce. The current, poor state understanding of these properties of defects in silicon poses both a challenge for fundamental semiconductor physics and a formidable obstacle for the development of predictive models of silicon bulk processing.

We investigate the relative stabilities of point defect clusters in Si with a new experimental approach using atomically-clean Si(111) surfaces as a sinks for vacancies and interstitials, coupled with simulations bridging multiple time scales. The arrival of a vacancy (interstitial) at an atomically-clean and flat surface would cause the disappearance (reappearance) of a surface atom. We measure net arrival rates of vacancies and interstitials directly, using the STM to count the number of atoms populating the surface layer after various stages of annealing at different temperatures. We find that after roomtemperature inradiation of $\mathrm{Si}(111)-7 \times 7$ by $5 \mathrm{keV}$ Ar or Xe ions at submonolayer doses, annealing at $350^{\circ} \mathrm{C}$ results in a decrease in the atomic population of the adatom layer, while subsequent annealing at $500^{\circ} \mathrm{C}$ restores the population of that layer.

Modeling of the formation and evolution of defects and defect clusters requires accurate representation and linking of two distinct time scales: (i) the initial cascade, creation, recombination, and clustering of point defects, culminating in the primary damage state (picoseconds), and (ii) the subsequent evolution of the damage under annealing, at experimentally-accessible time scales (seconds and hours.) MD simulations provide a three-dimensional representation of the location of all the defects induced by the implantation process and provide input to the Kinetic Monte Carlo (KMC) simulations, which describe defect evolution over time scales comparable to the experiments. Application of combined $\mathrm{MD}$ and $\mathrm{KMC}$ simulations shows that the experimental results can be explained by different rates of arrival to the surface of the vacancies and interstitials produced in the bulk during ion irradiation.

\section{EXPERIMENT}

The experiments were performed in an ultrahigh vacuum (UHV) system with base pressure below $10^{-10}$ torr. $\mathrm{Si}(111)$ samples cut from commercial wafers exhibited the 
$7 \times 7$ reconstruction in both Low Energy Electron Diffraction (LEED) and STM after annealing at $1250^{\circ} \mathrm{C}$ for 30 seconds and cooling to room temperature. The STM reveals that step bunching results in typical terrace lengths exceeding $1 \mu \mathrm{m}$, with occupation of over $99.7 \%$ of the atomic sites in the adatom layer, the outermost atomic layer and that which is imaged with the STM. Such surfaces were then exposed briefly to irradiation by $5 \mathrm{keV} \mathrm{Xe}$ ions, with a total dose of $\sim 1.5 \times 10^{13} \mathrm{~cm}^{-2}$, and imaged in situ by STM. After subsequent annealing cycles, the sample was always allowed to cool to room temperature before imaging. Sample temperatures during annealing were recorded with a pyrometer which was calibrated with a thermocouple, and are expected to be accuratewithin $20^{\circ} \mathrm{C}$.

\section{RESULTS}

(a)
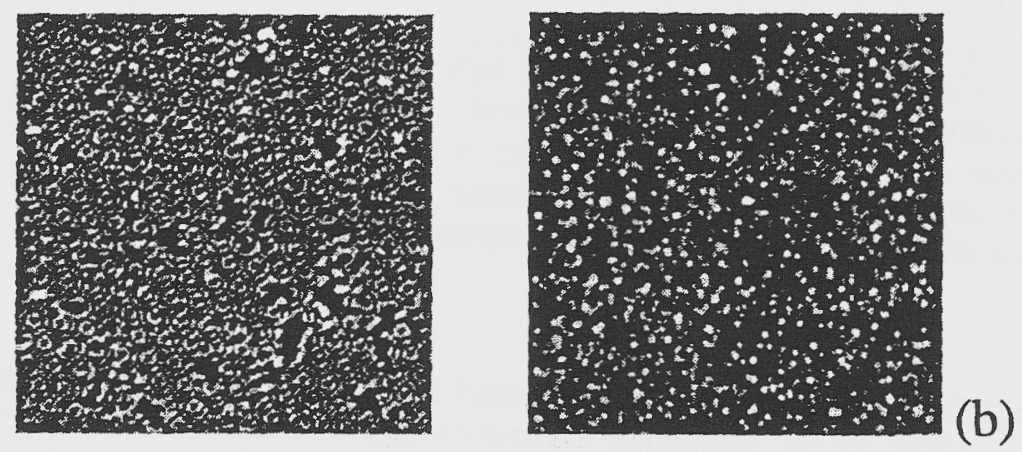

(c)
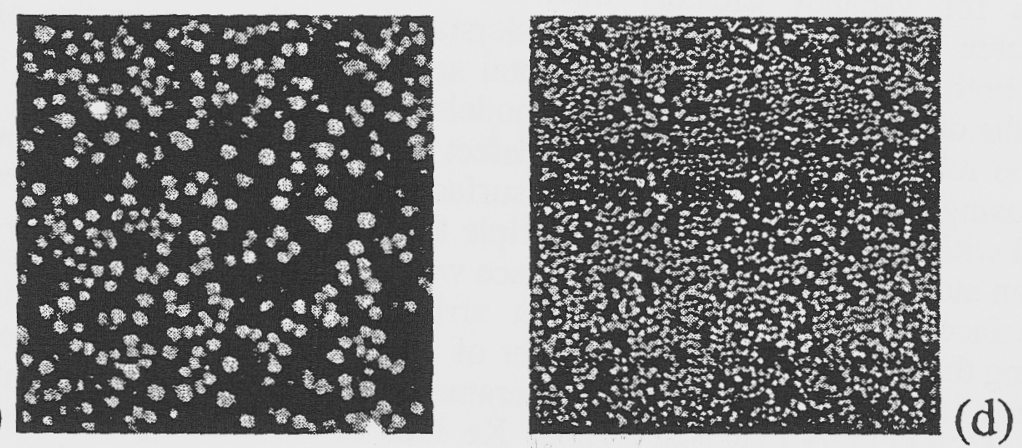

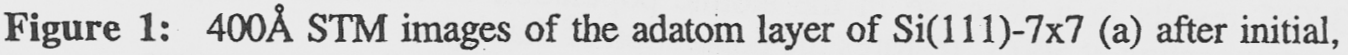
room-temperature irradiation by $5 \mathrm{keV} \mathrm{Xe}$ ions, at $1.5 \times 10^{13} \mathrm{~cm}^{-2}$, (b) after annealing at $350^{\circ} \mathrm{C}$ for 5 minutes and (c) after 4 hours, and (d) after annealing at $500^{\circ} \mathrm{C}$ for 2 minutes.

Figure 1(a) shows a $400 \AA$ STM image of $\mathrm{Si}(111)-7 \times 7$ immediately following irradiation by $5 \mathrm{keV} \mathrm{Xe}$ ions. While the irradiation has resulted in the disappearance of $8 \%$ of the atoms from the adatom layer, the long-range surface order is still present in both STM and LEED. Figures 1(b-d) display STM images following progressive stages of annealing of the surface irradiated with Xe ions. While we cannot image exactly the same location after each annealing cycle, we believe on the basis of measurements at various positions on the surface that regions which are imaged generally represent the morphological characteristics of the sample. Annealing at $350^{\circ} \mathrm{C}$ leads to disappearance of the adatoms from the surface. While those remaining still assume binding sites consistent with the $(7 \times 7)$ superlattice, the percentage of sites occupied drops from $92 \%$ 
immediately after irradiation to $35 \%$ after 5 minutes of annealing (fig. $1(\mathrm{~b})$ ), and to $28 \%$ after 4 hours of annealing (fig. 1(c)). Despite this depopulation of the adatom layer, the persistence of strong $7 \times 7$ periodicity in LEED indicates preservation of the crystalline order in the layers immediately below the adatom layer. Annealing smooth $\mathrm{Si}(111)-7 \times 7$ which has not been exposed to ion irradiation does not lead to adatom disappearance.

Annealing the same surface at $500^{\circ} \mathrm{C}$ for 2 minutes results in repopulation of $73 \%$ of the adatom layer, as in figure 1(d). The strong coherence of the reconstruction demonstrates that it was not disrupted by either the irradiation or the subsequent $350^{\circ} \mathrm{C}$ anneal. The observed saturation of the adatom layer's population around $75 \%$ at $500^{\circ} \mathrm{C}$ suggests that the repopulation does not result from adatom detachment at steps. We find neither adatom islands nor single-atomic height terraces at the base of step bunches.

Atomistic simulation of both ion implantation and the evolution of induced damage is consistent with a model in which the surface acts as a sink for bulk vacancies and interstitials. Classical MD simulations, with the Stillinger-Weber potential [6] for Si and a Universal pair potential [7] for $\mathrm{Si}-\mathrm{Xe}$, in computational boxes with up to $10^{6}$ atoms, are used to model the prompt $\left(10^{-11} \mathrm{~s}\right)$ displacement cascade process that gives rise to the primary state of damage. [8] The concentration of disorder in amorphous pockets and average sputter yield of 2.25 atoms/ion are consistent with previous reports $[9,10]$.

The dose of $1.5 \times 10^{13}$ ions $/ \mathrm{cm}^{2}$ is accumulated by incorporating 152 ion trajectories in a $0.32 \times 0.32 \times 5 \mu \mathrm{m}$ box which is used for $\mathrm{KMC}$ simulations. Defects produced by the implantation evolve during annealing through point defect diffusion, clustering and cluster evaporation [11], according to recently-calculated diffusivities for vacancies and interstitials in Table I $[5,12]$. The prefactor for the self interstitial diffusivity has been obtained by fitting KMC results to the diffusion of boron in silicon [12] and using $a b$ initio results for the energetics of the boron-silicon interaction [13]. Binding energies of larger clusters are fitted to the functional form: $\operatorname{EbV}(n)=3.6-4.9\left(n^{2 / 3}-(n-1)^{2 / 3}\right) \mathrm{eV}$ and $\operatorname{EbI}(n)=2.5-2.17\left(n^{1 / 2}-(n-1)^{1 / 2}\right) e V$, for $V$ and I clusters of size $n$, respectively [11].

\begin{tabular}{cccccc}
\hline \hline & & \multicolumn{4}{c}{ Binding Energies of Clusters } \\
\cline { 3 - 6 } & Diffusivity $\left(\mathrm{cm}^{2} / \mathrm{s}\right)$ & $\begin{array}{c}\text { Size } 2 \\
(\mathrm{eV})\end{array}$ & $\begin{array}{c}\text { Size 3 } \\
(\mathrm{eV})\end{array}$ & $\begin{array}{c}\text { Size 4 } \\
(\mathrm{eV})\end{array}$ & $\begin{array}{c}\text { Size 5 } \\
(\mathrm{eV})\end{array}$ \\
\hline Vacancy & $\begin{array}{c}0.001 \exp (-0.43 / \mathrm{KT}) \\
\text { Interstitial }\end{array}$ & 0.62 & 0.78 & 1.2 & 1.82 \\
\hline \hline
\end{tabular}

Table I. Kinetic parameters in KMC calculations, obtained from MD simulations using the Stillinger-Weber potential [5]. The pre-factor for Interstitial diffusivity was obtained by fitting $\mathrm{KMC}$ results to boron diffusion in silicon [12].

We first examine evolution of the damage produced by $5 \mathrm{keV}$ Xe during annealing at $350^{\circ} \mathrm{C}$. The $\mathrm{KMC}$ simulation first recombines all Frenkel (V-I) pairs within 1 nearestneighbor. Defects then migrate according to the rules in Table 1 . According to the simulations, at $350^{\circ} \mathrm{C}$ vacancies initially arrive at the surface at a greater rate than do interstitials. The number of vacancies reaching the surface after 4 hours' annealing at $350^{\circ} \mathrm{C}$ is greater than the number of interstitials. The surface vacancy density is then $0.8 \times 10^{14} / \mathrm{cm}^{2}$, in reasonable agreement with the experimental observation of $1.2 \times 10^{14} / \mathrm{cm}^{2}$, which in turn represents more than 6 excess vacancies per ion reaching 
the surface and greatly exceeds the sputter yield. We note that the total number of vacancies in the adatom layer is not a measure of the sputter yield.

The evolution of defects in the bulk proceeds in two stages: first, when both free vacancies and interstitials are present, the process is governed by the different mobilities of the defects. At $350^{\circ} \mathrm{C}$, the diffusivities of $\mathrm{V}$ and $\mathrm{I}$ are similar, and both diffuse and recombine in the bulk or at the surface. After $10^{-7} \mathrm{~s}$ only defect clusters remain in the bulk. In the second stage, corresponding to experimentally measurable times, defect evolution is governed by cluster binding energies. Interstitial clusters dissociate at a much lower rate than vacancies.

After annealing for four hours, $42 \%$ of the defects created initially have recombined in the bulk, leaving only $5 \mathrm{~V} / \mathrm{ion}$ and $9 \mathrm{I} / \mathrm{ion}$ in clusters. Increasing the temperature to $500^{\circ} \mathrm{C}$ induces dissociation of both vacancy and interstitial clusters. According to the simulations, all vacancies quickly disappear from the bulk, leaving only interstitial clusters, whose gradual dissolution releases interstitials which migrate to the surface and cause the observed recovery of the adatom layer. The simulations' predictions of the net numbers of defects appearing on the surface after various annealing times are compared with the experimental results in Table II.

(a)

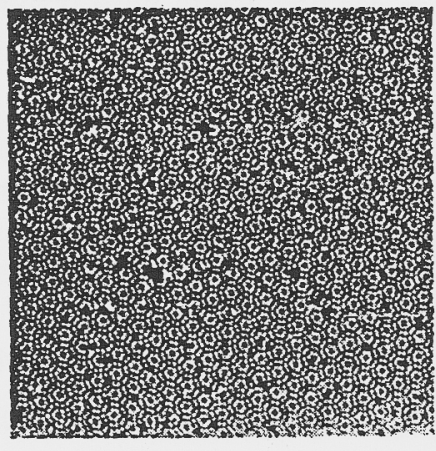

(c)

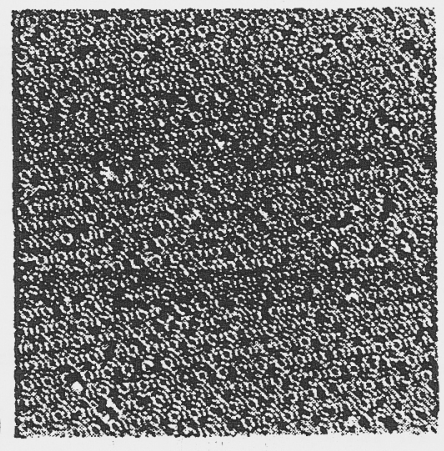

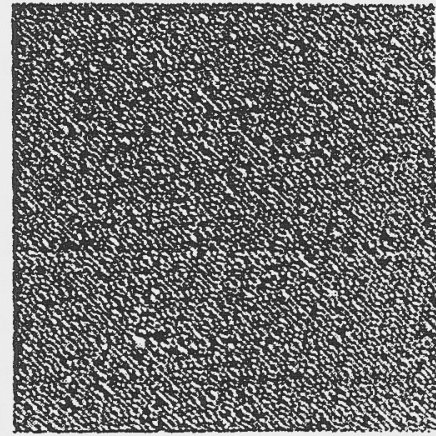

(b)

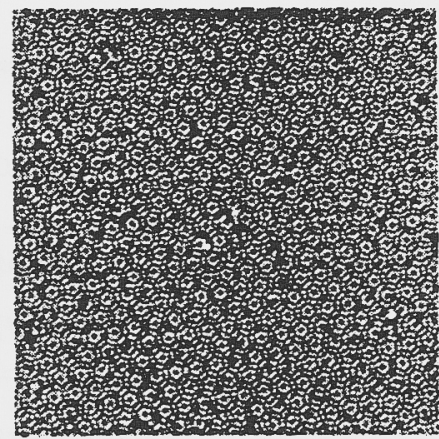

(d)

Figure 2: $500 \AA$ STM images of $\operatorname{Si}(111)-7 \times 7$ (a) following initial, roomtemperature irradiation by $5 \mathrm{keV}$ Ar ions, at $3.5 \times 10^{12} \mathrm{~cm}^{-2}$, (b) after annealing at $350^{\circ} \mathrm{C}$ for 90 seconds and (c) after 4 minutes, and (d) after annealing at $500^{\circ} \mathrm{C}$ for 4 minutes.

In order to ensure that the essential result does not arise from a unique combinatiori of ion energy and mass, a similar experiment was performed with a $5 \mathrm{keV}$ Ar ions instead of $\mathrm{Xe}$, and with a lower total dose of $3.5 \times 10^{12}$ ions $/ \mathrm{cm}^{2}$. Figure 2(a) shows a $500 \AA$ STM image of a $\mathrm{Si}(111)-7 \times 7$ surface immediately following the room-temperature $\mathrm{Ar}$ irradiation. In this case, $2.4 \%$ of the atoms in the adatom layer were missing after the 
irradiation. The number increased to $6.4 \%$ after $90 \mathrm{sec}$ at $350^{\circ} \mathrm{C}$ (figure $2(\mathrm{~b})$ ), and to $6.8 \%$ after 4 minutes at $350^{\circ} \mathrm{C}$ (figure $2(\mathrm{c})$ ), but dropped to $4.3 \%$ after 4 minutes at $500^{\circ} \mathrm{C}$. Corresponding, combined $\mathrm{MC}$ and $\mathrm{KMC}$ simulations for $5 \mathrm{keV}$ Ar impacts on $\mathrm{Si}(111)$ and subsequent annealing also predict a net surface segregation of vacancies at $350^{\circ} \mathrm{C}$, and a net arrival of interstitials at $500^{\circ} \mathrm{C}$ after the vacancy clusters have dissolved. The simulations' predictions of the net numbers of defects appearing on the surface after various annealing times are compared with the experimental results for this case in Table II below.

\begin{tabular}{|c|c|c|c|c|}
\hline \multirow[b]{2}{*}{$\begin{array}{c}\text { Room-Temp. } \\
\text { Irradiation }\end{array}$} & \multirow[b]{2}{*}{$\begin{array}{c}\text { Annealing } \\
\text { Temp. }\left({ }^{\circ} \mathrm{C}\right) \\
\end{array}$} & \multicolumn{3}{|c|}{$\begin{array}{c}\text { Surface } \\
\text { Defects } / \mathrm{cm}^{2}\end{array}$} \\
\hline & & $\begin{array}{c}\text { Annealing } \\
\text { Time }\end{array}$ & Experiment & Simulation \\
\hline $\begin{array}{c}5 \mathrm{keV} \mathrm{Xe} \\
1.7 \times 10^{13} / \mathrm{cm}^{2}\end{array}$ & $\begin{array}{l}350 \\
350 \\
500\end{array}$ & $\begin{array}{r}300 \\
14400 \\
240\end{array}$ & $\begin{array}{c}1.2 \times 10^{14} \mathrm{~V} \\
1.3 \times 10^{14} \mathrm{~V} \\
0.9 \times 10^{14} \mathrm{I}\end{array}$ & $\begin{array}{l}1.0 \times 10^{14} \mathrm{~V} \\
1.0 \times 10^{14} \mathrm{~V} \\
1.0 \times 10^{14} \mathrm{~V}\end{array}$ \\
\hline $\begin{array}{c}5 \mathrm{keV} \mathrm{Ar} \\
3.5 \times 10^{12} / \mathrm{cm}^{2}\end{array}$ & $\begin{array}{l}350 \\
350 \\
500\end{array}$ & $\begin{array}{r}90 \\
600 \\
240\end{array}$ & $\begin{array}{r}1.2 \times 10^{13} \mathrm{~V} \\
1.3 \times 10^{13} \mathrm{~V} \\
4.5 \times 10^{12} \mathrm{I}\end{array}$ & $\begin{array}{c}1.1 \times 10^{13} \mathrm{~V} \\
1.1 \times 10^{13} \mathrm{~V} \\
2.0 \times 10^{12} \mathrm{I}\end{array}$ \\
\hline
\end{tabular}

Table II: Comparison of experimentally observed surface defect densities for each of the conditions of irradiation and subsequent annealing described in the text, with defect densities predicted by the simulations. V = "Vacancies," and I = "Interstitials."

\section{CONCLUSIONS}

The observed depopulation of the Si (111)-7x7 adatom layer under annealing at $350^{\circ} \mathrm{C}$ following initial, room-temperature ion irradiation indicates a net surface accumulation of bulk vacancies created by the irradiation and results from the lower binding energy of vacancy clusters than for interstitial clusters. The repopulation of the adatom layer observed upon subsequent annealing at $500^{\circ} \mathrm{C}$ indicates a net arrival of bulk intersitials which gradually evaporate from the remaining clusters in the bulk after the less stable vacancy clusters have evaporated.

Annealing of damage induced by low-energy implantation in $\mathrm{Si}$ leads to the formation of vacancy and interstitial clusters within $\approx 1 \mu \mathrm{s}$. The kinetics of subsequent damage evolution are controlled by the relative stabilities of interstitial and vacancy clusters. Vacancy clusters, being less stable than interstitial clusters, dissolve at lower temperatures.

\section{ACKNOWLEDGMENTS}

The authors Pelaz for helpful discussions.

This work was performed under the auspices of the U.S. Department of Energy by the University of California, Lawrence Livermore National Laboratory under Contract No. W-7405-Eng-48. 


\section{REFERENCES}

1. J.D. Plummer, P.G. Griffin, Nucl. Instrum. Meth. B102, 160 (95).

2. U. Gösele and T.Y. Tan Diffusion in Solids, Unsolved Problems (Trans Tech. Publications, Zurich, 1992), p.189.

3. H.-J. Gossmann, P.A. Stolk, D.J. Eaglesham, G.H. Gilmer, and J.M. Poate, Process Physics and Modeling in Semiconductor Technology, editied by G.R. Srinivasan, C.S. Murthy, and S.T. Dunham (Electrochemical Society, Pennington, New Jersery, 1996).

4. U. Gösele, A. Plößl, and T.Y. Tan Process Physics and Modeling in Semiconductor Technology, edited by G.R. Srinivasan, C.S. Murthy and S.T. Dunham (Electrochemical Society, Pennington, New Jersey, 1996), p. 309.

5. G.H. Gilmer, T. Diaz de la Rubia, D. Stock and M. Jaraiz, Nucl. Instrum. and Methods B102, 247 (1995).

6. F.H. Stillinger and T.A. Weber, Phys. Rev. B31, 5262 (1985).

7. J.P. Biersack and J.F. Ziegler, Nucl. Instrum. and Methods. 194, 93 (1982).

8. M. J. Caturla, L. Marques, T. Diaz de la Rubia and G.H. Gilmer, Phys. Rev. B (in press).

9. J. Narayan, O.S. Oen, D. Fathy and O.W. Hollan, Materials Letters 3, 67 (1985).

10. P.C. Zalm, J.Appl. Phys. 54, 2660 (1983).

11. M. Jaraiz, G.H. Gilmer, J. M. Poate and T. Diaz de la Rubia, Appl. Phys. Lett. 68, 409 (1996).

12. L. Pelaz and G.H. Gilmer (private communication).

13. J. Zhu, T. Diaz de la Rubia, L. Yang, C. Mailhiot and G.H. Gilmer, Phys. Rev. B54, 4741 (1996). 